(SUNDROP): five years of screening with telemedicine. Ophthalmic Surg Lasers Imaging Retin. 2014;45:106-13.

10. Ells AL, Holmes JM, Astle WF, et al. Telemedicine approach to screening for severe retinopathy of prematurity: a pilot study. Ophthalmology. 2003;110:2113-7.

11. Chiang MF, Keenan JD, Starren J, et al. Accuracy and reliability of remote retinopathy of prematurity diagnosis. Arch Ophthalmol. 2006;124:322-7.

12. Wu C, Petersen RA, VanderVeen DK. RetCam imaging for retinopathy of prematurity screening. J AAPOS. 2006;10:107-11.

13. Dhaliwal C, Wright E, Graham C, McIntosh N, Fleck BW. Widefield digital retinal imaging versus binocular indirect ophthalmoscopy for retinopathy of prematurity screening: a two-observer prospective, randomised comparison. Br J Ophthalmol. 2009;93:355-9.

14. Dai S, Chow K, Vincent A. Efficacy of wide-field digital retinal imaging for retinopathy of prematurity screening. Clin Exp Ophthalmol. 2011;39:23-29.
15. Schwartz SD, Harrison SA, Ferrone PJ, Trese MT. Telemedical evaluation and management of retinopathy of prematurity using a fiberoptic digital fundus camera. Ophthalmology. 2000;107:25-28.

16. Lorenz B, Spasovska K, Elflein H, Schneider N. Wide-field digital imaging based telemedicine for screening for acute retinopathy of prematurity (ROP). Six-year results of a multicentre field study. Graefes Arch Clin Exp Ophthalmol. 2009;247:1251-62.

17. Coats DK, Miller AM, Brady McCreery KM, Holz ER, Paysse EA. Involution of threshold retinopathy of prematurity after diode laser photocoagulation. Ophthalmology. 2004;111:1894-8.

18. Coats DK, Miller AM, Hussein MA, McCreery KM, Holz E, Paysse EA. Involution of retinopathy of prematurity after laser treatment: factors associated with development of retinal detachment. Am J Ophthalmol. 2005;140:214-22.

\title{
Living with an artificial eye-the emotional and psychosocial impact
}

\author{
Edward Saxby ${ }^{1} \cdot$ Rhys Davies $^{2} \cdot$ Jan Kerr $^{3}$
}

Received: 20 January 2019 / Accepted: 31 January 2019 / Published online: 19 March 2019

(c) The Royal College of Ophthalmologists 2019

\section{Introduction}

The eye forms an integral part of our identity. However, they maybe removed due to specific indication: ocular tumours, irreparably damaged and painful globes or severe ocular infections. The loss of an eye can cause more anguish than simply the loss of vision, it can also affect our confidence, mental health and our quality of life [1].

Evidence indicates that patients living with anophthalmia have lower health-related quality of life scores. Patients own perceptions of their social relationships are negatively affected and they have been shown to suffer from anxiety and depression [2].

We evaluated the emotional and psychosocial well being of patients that had undergone either enucleation or

Edward Saxby

e_saxby@hotmail.com

1 Ophthalmology specialist trainee, Princess Alexandra Eye Pavilion, Chalmers Street, Edinburgh EH3 9HA, UK

2 Ophthalmology specialist trainee, Princess Alexandra Eye Pavilion, Chalmers Street, Edinburgh EH3 9HA, UK

3 Consultant Ophthalmologist, Princess Alexandra Eye Pavilion, Chalmers Street, Edinburgh EH3 9HA, UK evisceration to identify whether further emotional support or counselling would be beneficial.

\section{Method}

All patients over the age of 18 that had undergone either an evisceration or enucleation performed at the Princess Alexandra Eye Pavilion, Edinburgh between 1 January 2011 and 1 January 2018 were identified. Theatre online coding systems allowed us to identify the selected cohort. A telephone questionnaire (Fig. 1) was then conducted.

\section{Results}

Fifty two patients had undergone either enucleation or evisceration. Thirty nine patients were still living. We attempted to contact all 39 patients and received 25 responses (64\%).

Pain was identified as the overwhelming reason that patients underwent the operation (68\%) with more than half of our participants stating that preoperative pain was severe and interfering with daily activities. About $40 \%$ of patients indicated a loss of confidence as a result of the surgery, and a lack of emotional support was cited in $44 \%$ of patients (Fig. 2). One to one counselling sessions were stated as the most desired from of support both pre and postoperatively. 
Fig. 1 Evisceration/enucleation telephone interview sheet

\section{Evisceration/Enucleation Questionnaire}

1. What was the main reason for your decision to go ahead with the operation?
a. Pain
b. Appearance
c. Complicated eye care (clinic visits, hospital admissions)
d. Persuaded by other people

2. Did you suffer pain from the eye before the operation?
a. Not at all
b. Mild
c. Severe, interfering with daily activities

3. Did you suffer loss of confidence following the operation?
a. Not at all
b. Mild
c. Severe

4. How do you feel having had the surgery?
a. Wish I hadn't had the operation
b. Some regrets
c. No different
d. Pleased with the outcome
e. Wish I had it sooner

5. Before the surgery where did you get information on the operation and living with an artificial eye?
a. Eye clinic staff
b. GP
c. Internet
d. Others with an artificial eye
e. Artificial eye department

6. Did you receive enough information before the surgery?

a. Yes

b. No (If no what additional information would have been helpful)

7. Did you feel that the emotional side of the situation was adequately addressed for your needs?
a. Yes
b. No

8. If any, what additional support would have utilized

a. One to one sessions with a councilor

b. Informal chat with an artificial eye user

c. Contact group with others that had been through the same

9. Is there anything you wished you had known preoperatively?

\section{Discussion}

Pain is the predominant cause for most patients undergoing eye removal. Between $30 \%$ and $50 \%$ of patients suffering from chronic pain also struggle with depression and anxiety [3], therefore preoperatively we are already dealing with a cohort of people who are more likely to suffer from mental health illness.
Our study indicated that patients wanted to know more about the operation: the outcome, cosmesis and how the prosthesis will look and fit. As nearly half of patients requested more emotional support both pre and postoperatively it seems they were not adequately prepared for what was to come.

Anophthalmic patients have poorer health-related quality of life, poorer self-rated health and more perceived stress than the general population. In particular quality of life was 
Before the surgery where did you get information on the operation and living with an artificial eye?

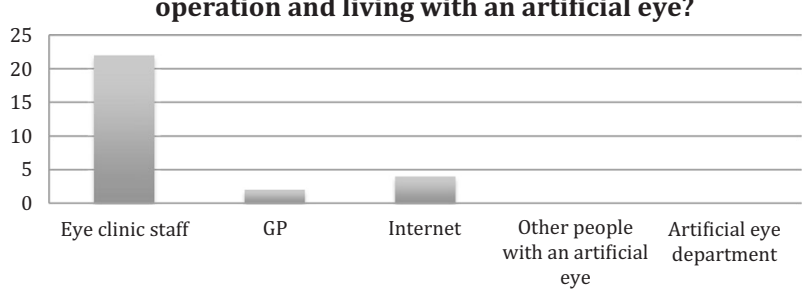

Did you feel that the emotional side of the situation was adequately addressed for your needs?

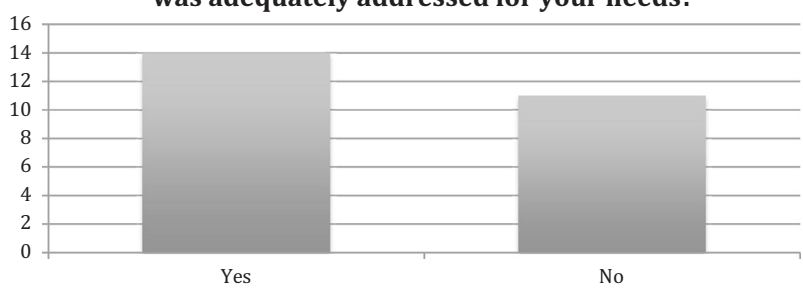

Fig. 2 Graphs showing confidence loss post surgery and adequately addressed emotional needs

limited by emotional problems and mental health disorders [4]. As mental illness remains the leading cause of years lived with disability worldwide [5] and the socioeconomic impact of depression on the UK alone has been estimated annually at over $£ 7$ billion [6], it is vital that we consider the emotional and psychosocial needs of our patients.

\section{Conclusion}

Loss of an eye and the use of artificial eyes have wide ranging emotional and psychosocial impact on patients. Care should not stop when the patient leaves the operating theatre. To maximise postoperative quality of life, a holistic approach, involving counsellors and psychotherapy is essential.

\section{Compliance with ethical standards}

Conflict of interest The authors declare that they have no conflict of interest.

Publisher's note: Springer Nature remains neutral with regard to jurisdictional claims in published maps and institutional affiliations.

\section{References}

1. Abdulkabir AA. Emotional, psychosocial and economic aspects of anophthalmos and artificial eye use. Int $\mathrm{J}$ Ophthal Vis Sci. 2008;7:1-7.

2. Ahn Jm LS, Yoon JS. Health-related quality of life and emotional status of anophthalmic patients in Korea. Am J Ophthalmol. 2010;149:1005-11.

3. Fishbain DGM, Meagher R, et al. Male and femal chronic pain patients categorized by DSM-II psychiatric diagnostic criteria. Pain. 1986;26:18-197.

4. Rasmussen ML. The eye amputated-consequences of eye amputation with emphasis on clinical aspects, phantom eye syndrome and quality of life. Acta Ophthalmol. 2010;88:1-26.

5. Whiteford HA, Degenhardt L, Rehm J, Baxter AJ, Ferrari AJ, Erskine HE. Global burden of disease attributable to mental and substance use disorders: findings from the Global Burden of Disease Study 2010. Lancet. 2013;382:1575-86.

6. Ardino VKM. Counselling and psychotherapy: is there an economic case for psychological interventions? London, UK: British Association for Counselling and Psychotherapy; 2013.

\title{
Raised intra-ocular pressure in the setting of Coffin-Siris syndrome
}

\author{
Michael James Dolaghan ${ }^{1} \cdot$ Sonia George ${ }^{1} \cdot$ Eibhlin McLoone $^{1}$
}

Received: 25 February 2019 / Accepted: 4 March 2019 / Published online: 26 March 2019

(c) The Royal College of Ophthalmologists 2019

Michael James Dolaghan mdolaghan01@qub.ac.uk

1 Department of Ophthalmology, Royal Victoria Hospital, Belfast Heath and Social Care Trust, Antrim, UK
Coffin-Siris syndrome (CSS) is a rare heterogenous genetic disorder first described in 1970. The diagnosis is considered in children with cognitive/developmental delay, 5th finger hypoplasia and characteristic facial features. There is, however, significant variability in the phenotypic appearance, making clinical diagnosis challenging $[1,2]$. 